\title{
Are Religious Customers Skeptical Toward Sexually Appealing Advertising? An Abstract
}

\author{
Catur Sugiarto and Virginie de Barnier
}

\begin{abstract}
The use of erotic content in advertising remains controversial, and marketers seemingly face some problems because the massive use of such type of ads leads to offending customers, potential backlashes (Reichert et al. 2011), ethical problems (Latour and Henthorne 1994), and leaving consumers feeling manipulated (Sengupta and Dahl 2008). This research explores the consumer response toward sex appeal in advertising and investigates ad skepticism in a culturally diverse context. Moreover, this study addresses the informants' opinions regarding the extent of graphic nudity and how religiosity influences their attitudes toward such ads. Semistructured in-depth interviews with 23 informants from four groups-academia, advertising practitioners, religious figures, and general consumers - were conducted. Findings relate the role of religiosity vis-à-vis nudity and the "lowering of the gaze" concept in Islam, the objectification and stereotypical portrayals of women, the irrational depiction of sexuality and intimacy, and factors that lead to contextual interpretation. The result provides further evidence that skepticism does not only exist on a cognitive basis but also on an emotional level as a response to the unrealistic and irritating claims made in some adverts. This study suggests that advertisers should advance their cultural comprehension by taking into account the moral and social differences.
\end{abstract}

References Available Upon Request

\footnotetext{
C. Sugiarto $(\square)$

Aix-Marseille Graduate School of Management-IAE, Aix-Marseille Université, CERGAM (EA 4225), Aix en Provence, France

Universitas Sebelas Maret, Surakarta, Indonesia

e-mail: catur.sugiarto@iae-aix.com

V. de Barnier

Aix-Marseille Graduate School of Management-IAE, Aix-Marseille Université, CERGAM (EA 4225), Aix en Provence, France

e-mail: virginie.de-barnier@iae-aix.com 